\title{
A Bronchoscopic Steam Thermal Ablation (BTVA) Case Report in A 85-Year-Old Male Clinically Compromised
}

Roberto Marchese ( $\nabla$ momarc313@yahoo.it)

Private Hospital La Maddalena: Casa di Cura La Maddalena SpA https://orcid.org/0000-0001-66375428

\section{Federica Scaduto}

Private Hospital La Maddalena: Casa di Cura La Maddalena SpA

Chiara Lo Nigro

Private Hospital La Maddalena: Casa di Cura La Maddalena SpA

\section{Case report}

Keywords: COPD, BTVA, bronchoscopy, lung volume reduction, emphysema.

Posted Date: October 1st, 2020

DOI: https://doi.org/10.21203/rs.3.rs-70797/v1

License: (c) (1) This work is licensed under a Creative Commons Attribution 4.0 International License. Read Full License 


\section{Abstract}

Background: Bronchoscopic lung volume reduction (BLVR) techniques improve lung function and increase exercise tolerance in patients with chronic obstructive pulmonary disease (COPD) and BLVR treatment is included in the Global Initiative for Chronic Obstructive Lung Disease (GOLD) treatment guidelines for these patients. BTVA (Intervapor Uptake Medical, Tustin, CA, USA) represents a recent therapy of this group that allows to treat sublobar areas and for this reason is used clinically compromised patients, like in this case report.

Case presentation: In this paper we describe a case report of an 85-year-old male with severe respiratory failure and a diagnosis of emphysema presented with dyspnea and clinical worsening, despite the best medical therapy practiced. For comorbidity and pathology's features he was excluded from surgical treatment options, like lung volume reduction surgical (LVRS) and from positioning of endobronchial valves (EBV) for the presence of collateral ventilation and he was addressed to BTVA. The procedure was successful for this patient.

Conclusions: This case supports recent suggestions that BTVA can be a good alternative treatment for patients properly selected.

\section{Background}

BLVR treatment is included in the GOLD treatment guidelines for COPD patients (1). The most used devices are endobronchial valves (EBV) $(2,3,4)$, used for the first time in 2002 , but this treatment is reserved to patients with emphysema with no collateral ventilation (CV) and integrity of the interlobar fissures (IF) at the chest computed tomography (CT). For emphysematous patients without these features there are alternative devices $(5,6)$. BTVA (Intervapor Uptake Medical, Tustin, CA, USA) represents a recent alternative therapy for these patients that uses high temperature water vapor to induce parenchymal thermal damage and inflammation resulting in fibrosis and volume reduction in the treated area, independently from interlobar CV $(7,8,9)$.

\section{Case Presentation}

An 85-year-old male was admitted to our clinic (April 2019) with diagnosis of COPD (GOLD D). He had a history of arterial blood hypertension and hyperuricemia. A family history of lung tumor (brother), nor of drug allergies. He was a former smoker of 60 pack years (stop smoking 20 years prior). He had important dyspnea at rest $(\mathrm{mMRC}>3)$ despite optimal pharmacotherapy (aclidinium bromide and salmeterolo/fluticasone) two times daily, teofilline, prednisone as needed and continuous $6 \mathrm{~L} / \mathrm{min}$ of oxygen.

Pulmonary function test (PFT): ratio of forced expiratory volume in $1 \mathrm{~s}$ (FEV1) to forced vital capacity (FVC) was $51 \%$, FEV1 was $1.29 \mathrm{~L}$ (percentage of predicted FEV1, 56\%), residual volume (RV) was $3.96 \mathrm{~L}$ (percentage of predicted RV, 140\%); the total lung capacity (TLC) was $7.50 \mathrm{~L}$ (percentage of predicted 
TLC, $118 \%$ ), and the percentage of predicted diffusing capacity of carbon monoxide (DLCO) was $21 \%$. Arterial blood gas analysis revealed a pH of 7.37, $\mathrm{PaCO} 2$ of $46.4 \mathrm{mmHg}$ and $\mathrm{PaO} 2$ of $61.8 \mathrm{mmHg}, \mathrm{SaO} 2$ $92.4 \%$ in room air. At 6MWT he walked greater than $140 \mathrm{mt}$ (about $160 \mathrm{mt}$ ). St George Respiratory questionnaire (SGRQ) was calculated. Echocardiography shows an ejection fraction of $>55 \%$, with normal left and right ventricular size, normal PAPS.

CT performed in July 2019 indicated severe and heterogeneous pan-lobular emphysema with higher prevalence in upper lobes (UL) (Figs. 1).

In order to perform BLVR, the CT scan was analyzed by a dedicated software (VIDA Diagnostics, Coralville, IA, USA) measuring disease severity of each segment for identify the target area. The software showed a difference in lung density between targeted UL segment and its respective lower lobe and absence of IF. For this reason, LVRS and EBV weren't taken into consideration and BTVA was proposed as an alternative.

After placing an endoscopic catheter, a balloon was inflated in order to occlude the target segment and water heated vapor was delivered, $8.5 \mathrm{cal} / \mathrm{g}$ dose, first in LB1 + 2a for $6.1 \mathrm{~s}$. Afterwards the balloon was deflated and the catheter was inserted into the other sub-segmentary bronchus LB1 $+2 b$ for $3.6 s$ to complete the treatment of LB $1+2 \mathrm{a}-\mathrm{b}$ (Figs. 2).

The total procedure time was about $10 \mathrm{~min}$. The treatment was performed in rigid bronchoscopy under general anesthesia, in order to suppress the cough that could displaced the balloon.

After the procedure an increase in the inflammatory markers (PCR $5.48 \mathrm{mg} / \mathrm{dl} \mathrm{vs} 0.5 \mathrm{mg} / \mathrm{dl}$ at admission, PCT $0.13 \mu \mathrm{g} / \mathrm{L}$ vs $0.02 \mu \mathrm{g} / \mathrm{L}$ ) was found.

The CT scan performed after BTVA (Figs. 3) showed a parenchymal pulmonary inflammatory response of the apicodorsal segment of the left UL, with consequent reduction of lung volume (10). No adverse events were recorded (11). The patient was discharged at home in post operative day 8.

PFT was performed at 3 months after BTVA (October 2019). FEV1/FVC increased from 51 to $73 \%$, FEV1 increased by $560 \mathrm{~mL}$ from $1.29 \mathrm{~L}$ (percentage of predicted FEV $56 \%$ ) to $1.86 \mathrm{~L}(82 \%)$, RV decreased from $3.96 \mathrm{~L}$ (percentage of predicted RV, $140 \%$ ) to $3.22 \mathrm{~L}(113 \%)$, TLC decreased from $7.50 \mathrm{~L}$ (percentage of predicted TLC, $118 \%$ ) to $6.76 \mathrm{~L}(107 \%)$. The symptoms and quality of life improved markedly (SGRQ-C $\leq-8$ points). The oxygen therapy was reduced to $1 \mathrm{~L} / \mathrm{min}$.

During the follow-up (November 2019) he performed CT scan that identified a subpleural lung nodule in the posterior segment of the RUL (SUV 2.3).

On January 2019 a lung biopsy-CT guided was performed. The histological examination showed a carcinoma (CK7+, TTF1-, P40-.) The patient was candidate to thermoablation because of the concomitant pathologies. 


\section{Discussion And Conclusion}

BTVA represents a valid alternative to EBV that allows to treat only the most damaged lung segments of patients with heterogeneous emphysema. In 2009, Snell et al $(12,13)$ proposed the use of BTVA. STEPUP is the most important randomized, controlled open label trial $(14,15)$, that shows significant difference in FEV1 and SGRQ at 6 and 12 months (16). In this trial patient have a mean FEV1 of 33\% and a mean VR of $235 \%$ and undergone to a first treatment of 1 emphysematous segment of an upper lobe and then of one emphysematous segments in the contralateral upper lobe after 12 weeks. After 6 months there were statistically significant difference in FEV1 and SGRQ. Data obtained at the 12-month follow-up visits showed persistent improvements in lung function relative to baseline.

While Gompelmann et al $(17,18)$ have emphasized that patients should have $20 \%>$ FEV $1<45 \%$ of predicted values, RV $>175 \%$ of predicted values and DLCO $\geq 20 \%$ of predicted values and the patient had higher FEV1 and lower RV values, the outcome of the procedure was excellent.

As helium dilution technique was used to perform PFT, it's possible that RV values are underestimated compared to the same values calculated with plethysmography. This suggest that is important use the latter technique to perform PFT.

Despite we treat only sub-segmentary bronchus LB $1+2 a-b$, because of the patient critical issue, an extraordinary result has been achieved.

This case supports recent suggestions that BTVA can result in a good alternative treatment for patients properly selected and that minimally invasive treatments are an important resource in managing compromised patients.

\section{List Of Abbreviations}

BLVR: bronchoscopic lung volume reduction

COPD: chronic obstructive pulmonary disease

GOLD: global initiative for chronic obstructive lung disease

LVRS: lung volume reduction surgical

EBV: endobronchial valves

BTVA: bronchoscopic steam thermal ablation

CV: collateral ventilation

IF: integrity of the interlobar fissures

CT: chest computed tomography 
mMRC: Modified British Medical Research council questionnaire

PFT: Pulmonary function test

FEV1: forced expiratory volume in $1 \mathrm{~s}$

FVC: forced vital capacity

$\mathrm{RV}$ : residual volume

TLC: the total lung capacity

DLCO: diffusing capacity of carbon monoxide

6MWT: six minute walking test

SGRQ: St George Respiratory questionnaire

PAPS: pulmonary artery systolic pression

UL: upper lobes

LB: left bronchus

\section{Declarations}

Ethics approval and consent to participate

This is a case report that and not require approval by the institute's committee on human research.

\section{Consent for publication}

The patient has given written informed consent to publish this case (including publication of images).

\section{Availability of data and materials}

Data sharing is not applicable to this article as no datasets were generated or analysed during the current study.

\section{Competing interests}

The authors declare that they have no competing interests.

\section{Funding}

The authors declare that they have no funding 


\section{Authors' Contributions}

F. Scaduto: writing

C. Lo Nigro: procedure executor

R. Marchese: procedure executor, writing

\section{Acknowledgement}

A special thanks to professor Sebastiano Mercadante for his revision of the manuscript.

\section{Footnotes}

The authors have no conflicts of interest to declare.

\section{References}

1. Neumeier A1,2, Keith R1,3 Hosp Med. Clinical Guideline Highlights for the Hospitalist: The GOLD and NICE Guidelines for the Management of COPD. 2020;15:e1-e2.

2. Davey $C$, Zoumot Z, Jordan S et al. Bronchoscopiclung volume reductionwith endobronchial valves for patients with heterogeneous emphysema and intact interlobar fissures (the BeLieVeR-HIFi study): a randomised controlled trial. Lancet. 2015;386:1066-73.

3. Klooster K, ten Hacken NH, Hartman JE, Kerstjens HA, van Rikxoort EM, Slebos DJ. EndobronchialValvesfor Emphysema without Interlobar Collateral Ventilation. N Engl J Med. 2015;373:2325-35.

4. Koster TD, Slebos DJ. Thefissure: interlobar collateral ventilation and implications for endoscopic therapy in emphysema. Int J Chron Obstruct Pulmon Dis. 2016;11:765-73.

5. Gompelmann D1, Eberhardt R1, Herth FJ1. Novel Endoscopic Approaches to Treating Chronic Obstructive Pulmonary Disease and Emphysema. Semin Respir Crit Care Med.2015;36:609-15.

6. Xu W1,Wang J, He X et al. Bronchoscopic lung volume reduction procedures for emphysema: A network meta-analysis. Medicine (Baltimore). 2020;99:e18936.

7. Bandyopadhyay S, Henne E, Gupta A et al. Segmentalapproach to lung volume reduction therapy for emphysema patients. Respiration. 2015;89:76-81.

8. Herth FJ1, Ernst A, Baker KM et al. Characterization of outcomes 1 year after endoscopic thermal vapor ablation for patients with heterogeneous emphysema. G. Int J Chron Obstruct Pulmon Dis. 2012;7:397-405. 
9. Pu J, Wang Z, Gu S et al. Pulmonaryfissureintegrity and collateral ventilation in COPD patients. PLoS One. 2014;9:e96631.

10. Gompelmann D, Eberhardt R, Ernst A et al. The localizedinflammatory response to bronchoscopic thermal vapor ablation. 2013;86:324-31.

11. Emery MJ, Eveland RL, Eveland K et al. Lungvolume reduction by bronchoscopic administration of steam. Am J Respir Crit Care Med. 2010;182:1282-91.

12. Snell GI, Hopkins P, Westall G et al. A feasibility and safety study of bronchoscopic thermal vapor ablation: a novel emphysema therapy. Ann Thorac Surg 2009;88:1993-1998.

13. Snell G, Herth FJ, Hopkins P et al. Bronchoscopicthermal vapour ablation therapy in the management of heterogeneous emphysema. Eur Respir J. 2012;39:1326-33.

14. Valipour A,Herth FJ, Eberhardt $\mathrm{R}$ et al. Design of the randomized, controlled sequential staged treatment of emphysema with upper lobe predominance (STEP-UP) study. BMC Pulm Med. 2014;14:190.

15. Herth FJ, Valipour A, Shah PL et al. Segmentalvolumereductionusingthermalvapourablation in patients with severe emphysema: 6-month results of the multicentre, parallel-group, open-label, randomised controlled STEP-UP trial. Lancet Respir Med. 2016;4:185-93.

16. Shah PL1,Gompelmann D2, Valipour A3 et al.

Thermal vapour ablation to reduce segmental volume in patients with severe emphysema: STEP-UP 12 month results. Lancet Respir Med. 2016;4:e44-e45.

17. Gompelmann D1,2, Shah PL3,4,5, Valipour A6et al. Bronchoscopic Thermal Vapor Ablation: Best Practice Recommendations from an Expert Panel on Endoscopic Lung Volume Reduction. 2018;95:392-400.

18. Gompelmann D, Eberhardt R, Herth FJ. Technologyupdate: bronchoscopic thermal vapor ablation for managing severe emphysema. Med Devices (Auckl). 2014;7:335-341.

\section{Figures}




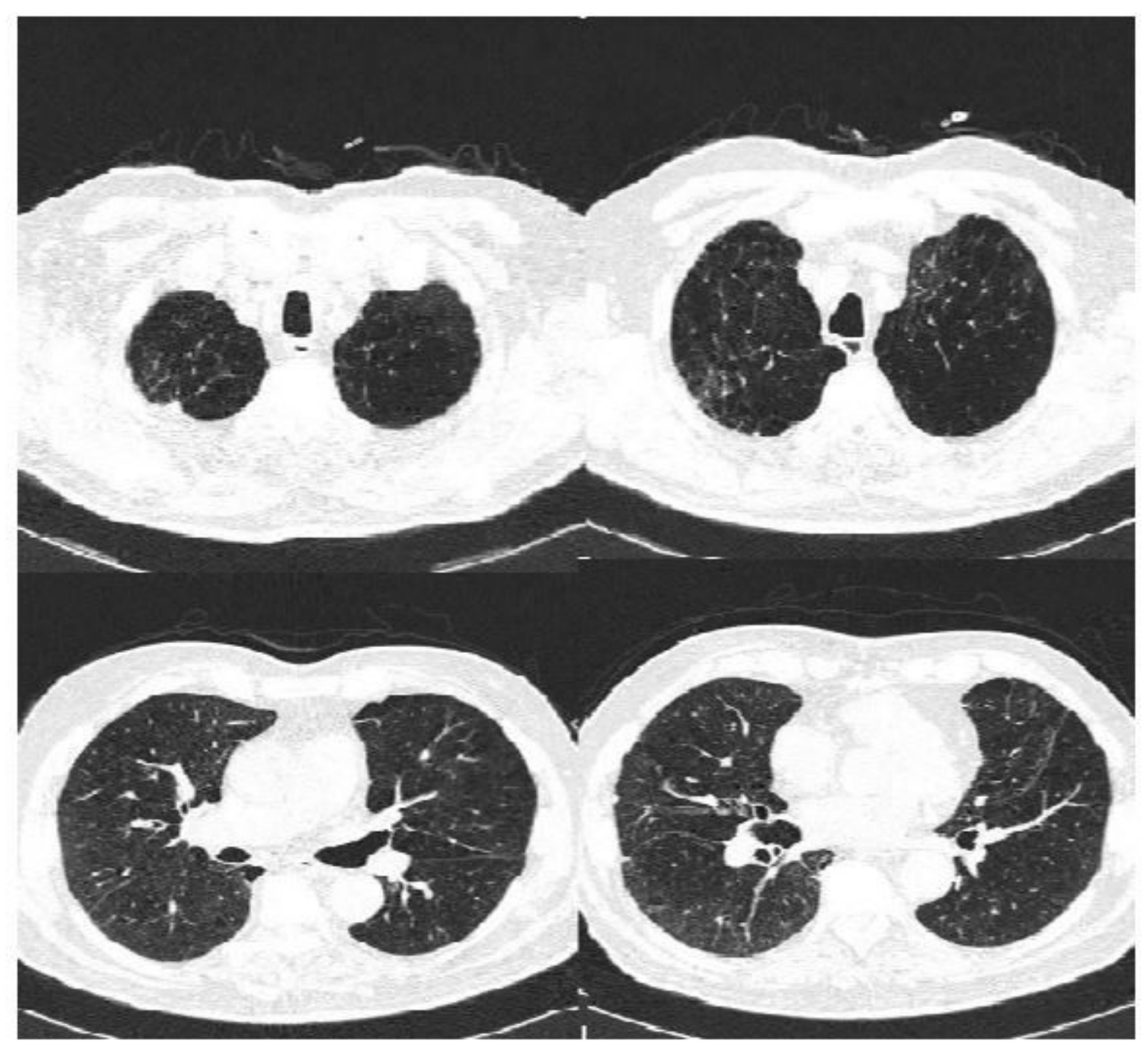

Figure 1

CT performed in July 2019 indicated severe and heterogeneous pan-lobular emphysema in both lungs, with higher prevalence in upper lobes (UL). 


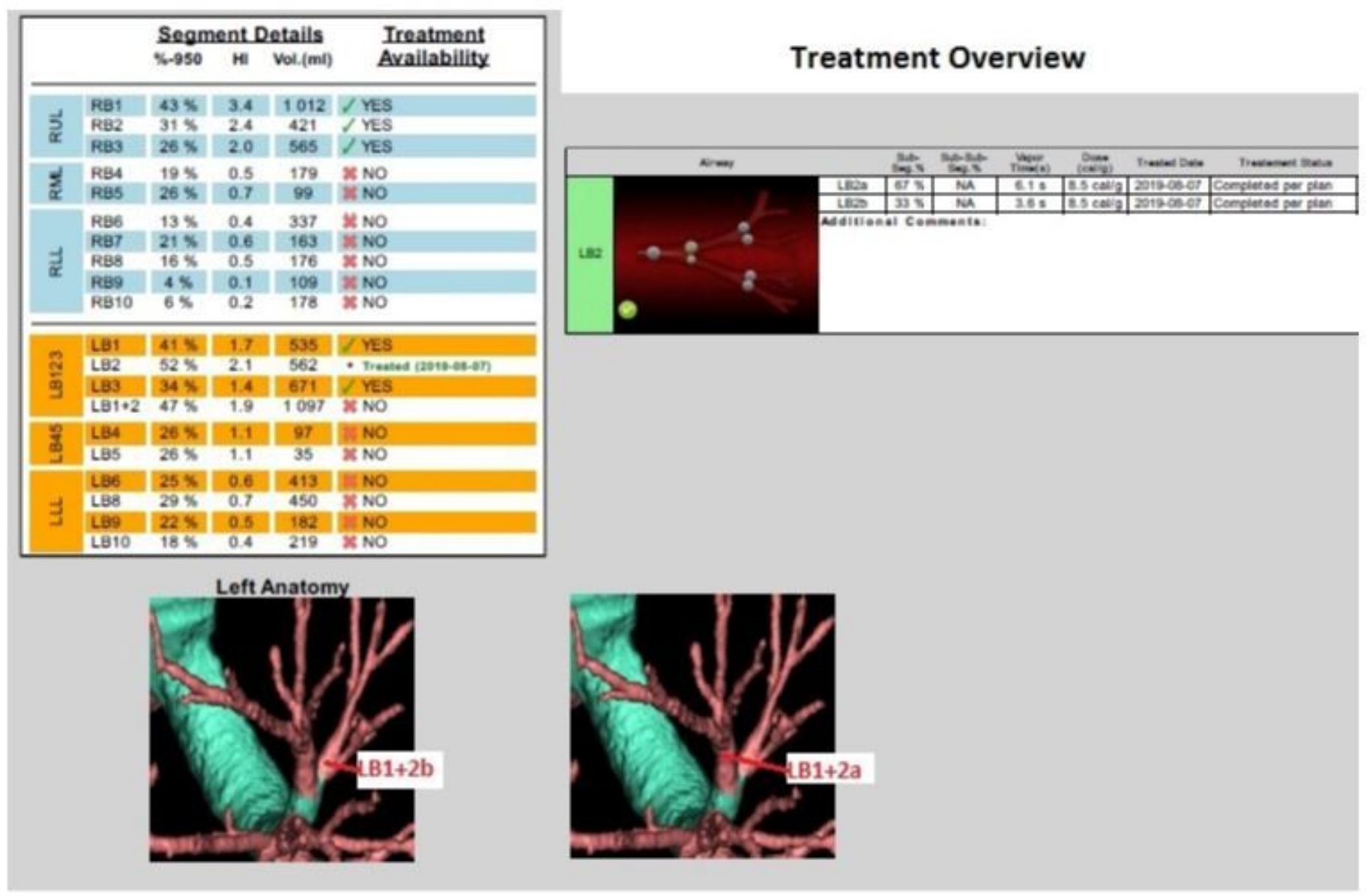

\section{Figure 2}

BTVA plan to treat LB $1+2 \mathrm{a}-\mathrm{b}$. After placing an endoscopic catheter, a balloon was inflated in order to occlude the target segment and water heated vapor was delivered, $8.5 \mathrm{cal} / \mathrm{g}$ dose, first in LB2a for $6.1 \mathrm{~s}$. Afterwards the balloon was deflated and the catheter was inserted into the other sub-segmentary bronchus LB2b for $3.6 s$ to complete the treatment of LB $1+2 a-b$ 


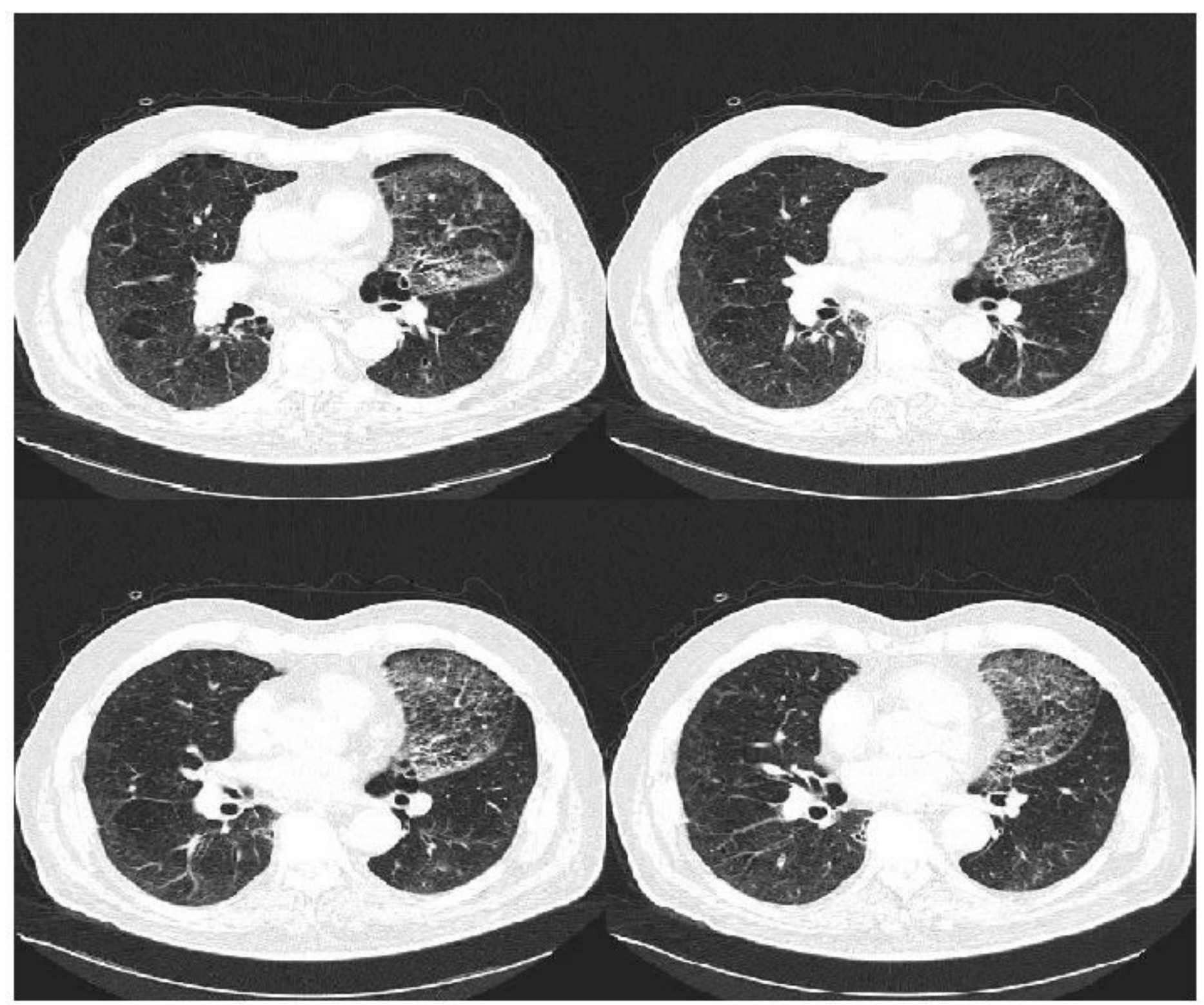

Figure 3

The CT scan performed after BTVA procedure shows a parenchymal pulmonary inflammatory response of the anterior segment of the left UL, with consequent reduction 